\title{
Benefficial effect of plant extracts in rabbit husbandry
}

\author{
Renáta Szabóová ${ }^{1}$, Andrea Lauková ${ }^{1}$, Lubica Chrastinová2, Viola Strompfová ${ }^{\text {, Monika }}$ \\ Pogány Simonová ${ }^{1}$, Iveta Plachá1, Zuzana Vasilková ${ }^{3}$, Mária Chrenková ${ }^{2}$, Štefan Faix ${ }^{1}$ \\ ${ }^{1}$ Slovak Academy of Sciences, Institute of Animal Physiology, Košice, Slovak Republic \\ ${ }^{2}$ Animal Production Research Centre, Institute of Nutrition, Nitra, Slovak Republic \\ ${ }^{3}$ Slovak Academy of Science, Institute of Parasitology, Košice, Slovak Republic
}

Received November 19, 2010

Accepted May 16, 2012

\begin{abstract}
The present study evaluates the effect of plant extracts of oregano and commercial Xtrakt ${ }^{\mathrm{TM}}$ administrations on microbial, biochemical, immunological and nutritional indicators and on Eimeria sp. oocyst occurrence in rabbits. Rabbits ( 5 weeks old, Hy-plus hybrid, $\mathrm{n}=66$ ) were divided into experimental group 1 (E1) with oregano extract application, experimental group 2 (E2) with Xtract ${ }^{\mathrm{TM}}$ application and control group. Natural substances were administered for the first 21 days. The experiment lasted for 42 days. The antibacterial effect was determined by the decrease of coagulase-positive staphylococci in E1 compared to control at day 42. Staphylococcus aureus cells were detected in lower counts in E2 compared to control at day 21. The counts of Clostridium-like bacteria were lower in both experimental groups at day 21 compared to day 7 (difference 1.2 and $1.3 \log$ cycles, respectively) and to control (difference 0.5 and $0.3 \log$ cycles, respectively). At day 7, the counts of coliforms in E1 were significantly lower than in E2 $(P<0.01)$. In rabbits fed with oregano, reduction of Eimeria sp. oocysts and higher value of phagocytic activity $(21.6 \pm 0.51 \%)$ were found compared to $\mathrm{Xtract}^{\mathrm{TM}}$, and prolonged immunostimulatory effect was noted. In the animals of both experimental groups higher final weight, feed conversion ratio and lower mortality were achieved compared to control. The administration of oregano showed antibacterial, anticoccidial, and immunomodulatory effects. The results showed that oregano administration may be used as an alternative prophylactic measure in rabbits.
\end{abstract}

Origanum vulgare, antimicrobial activity, Eimeria sp., animal, immunity

Plant extracts have been used for a wide variety of purposes for millennia (Jones 1996). The antimicrobial activity of plant oils and extracts has formed the basis for many administrations, including raw and processed food preservation, pharmaceuticals, alternative medicine and natural therapies (Lis-Balchin and Deans 1997). Oregano (Origanum vulgare) is an important member of the Lamiaceae (Labiatae) family that comprises about 900 species, over $75 \%$ of which are concentrated in the East Mediterranean subregion. The major essential oil constituents of oregano are carvacrol, thymol, $\gamma$-terpinene and $p$-cymene, range between $80.2 \%$ and $98.4 \%$ of total essential oils, with carvacrol yielding as much as $95 \%$ in oregano samples (O. vulgare subsp. Hirtum; Goliaris et al. 2002). The essential extracts derived from oregano are known to possess antimicrobial (Lambert et al. 2001) and antioxidant (Sarac et al. 2009) activities. Oregano has been examined as an alternative growth promoter in broiler chickens (Lewis et al. 2003), broiler turkeys and pigs (Marcin et al. 2006a). Enteric diseases frequently occur in rabbits around the weaning period, leading to an extensive use of antibiotics. Therefore, new and safe antimicrobial agents are searched for to prevent and/or overcome infections.

Based on our previous in vitro results (Szabóová et al. 2008), it seems that the use of phyto-additives and their extracts in rabbit husbandry offers an acceptable way to improve welfare and health. From this point of view, the objective of our study was to test the effect of oregano plant extract in rabbits as well as to test the effect of commercially used phytoadditive mixture Xtract ${ }^{\mathrm{TM}}$ (involving carvacrol, capsicum oleoresin, cinnamaldehyd). Our

Address for correspondence:

Renáta Szabóová

Institute of Animal Physiology, Slovak Academy of Sciences

Soltésovej 4-6, 04001 Košice, Slovakia
Phone: $+421-55-6330283$
Fax: +421-55-7287842
E-mail: szaboova@saske.sk
http://actavet.vfu.cz/ 
model study was focused on the microbiota in the intestinal tract of rabbits; the impact on nutritional, immunological and biochemical blood indicators; occurence of Eimeria sp. oocysts and oxidative stress.

\section{Material and Methods}

Experimental design

Sixty-six rabbits ( 35 days old, male sex, Hy-plus hybrid) were divided into 2 experimental (E1, E2) and 1 control group (C) of 22 rabbits each. Rabbits were kept in standard cages, two animals per cage. The experiment was performed on the farm of the Institute of Nutrition, Animal Production Research Centre, Nitra, Slovak Republic. All care and experimental procedures involving animals followed the European Commission guidelines (EEC Directive-86/609) with approval of the State Veterinary and Food Administration of the Slovak Republic. All animals were fed the commercial diet for growing rabbits (AnproFeed, VKZ Bučany, Slovakia; Table 1). The animals in group E1 received the oregano plant extract containing carvacrol $55 \pm 3 \%$ (gas chromatography analysis; density: $0.959 \pm 0.002 \mathrm{~g} / \mathrm{cm}^{3}$; refractive index: $1.515 \pm 0.001$; Calendula a.s., Nová L'ubovňa, Slovakia) at a dose of $10 \mu \mathrm{l}$ for animal/day in water. The animals had ad libitum access to water during the whole experiment. The dosage of plant extract was based on our previous in vitro tests (Szabóová et al. 2008). The feed for rabbits in group E2 was supplemented with commonly fed Xtract ${ }^{\mathrm{TM}}$ of $15 \mathrm{~g} / 100 \mathrm{~kg}$ feed (Pancosma, Switzerland), a mixture of plant extracts consisting of $5.4 \%(\mathrm{wt} / \mathrm{wt})$ carvacrol $\left(\mathrm{C}_{10} \mathrm{H}_{14} \mathrm{O}\right.$; from oregano Origanum spp.), $3.2 \%$ (wt/wt) cinnamaldehyde $\left(\mathrm{C}_{9} \mathrm{H}_{8} \mathrm{O}\right.$, from cinnamon Cinnamonum spp.) and $2.2 \%(\mathrm{wt} / \mathrm{wt})$ capsicum oleoresin $\left(\mathrm{C}_{18} \mathrm{H}_{27} \mathrm{NO}_{3}\right.$ from Mexican pepper Capsicum annuum). Oregano extract and $\mathrm{Xtract}^{\mathrm{TM}}$ were administered from the beginning of the experiment (day 0 , age of rabbits 35 days) in the duration of 21 days (day 21). The experiment lasted for 42 days.

Table 1. Ingredients, chemical composition and nutritive value of diets used for rabbits

\begin{tabular}{lrlr}
\hline Ingredients (\%) & \multicolumn{2}{c}{ Composition $(\mathrm{g} / \mathrm{kg})$} \\
\hline Clover (grass) meal & 27.00 & Crude protein & 197.00 \\
Extracted sugar beet pulp & 10.00 & Crude fibre & 166.50 \\
Barley & 15.00 & Crude fat & 39.00 \\
Oats & 13.00 & Ash & 80.00 \\
Wheat bran & 6.00 & Organic matter & 921.00 \\
Soybean meal & 7.50 & Starch & 178.00 \\
Sunflower meal & 14.00 & Lysine & 7.50 \\
Monocalcium phosphate & 0.60 & Methionine+cysteine & 6.50 \\
Dicalcium carbonate & 0.90 & Cholinchloride & 0.80 \\
Salt & 0.30 & ME (MJ $/ \mathrm{kg})$ & 10.0 \\
Carob-breadfruit of Ceratonia siliqua & 2.50 & & \\
DL-Methionine+wheat meal & $0.10+0.10$ & & \\
Mineral and vitamin premix & & & \\
\hline
\end{tabular}

${ }^{1}$ Premix (per kg diet): vitamin A (10.000 IU); vitamin D3 (2.000 IU); vitamin E acetate (30 mg); vitamin B2 (5 mg); vitamin B6 (2 mg); vitamin B12 (8 mg); Ca (9.25 g); P (6.2 g); Na (1.6 g); Mg (1.0 g); K (10.8 g); Fe (327.5 mg); Mn (80 mg); Zn (0.7 mg); ME - metabolisable energy

Bacterial monitoring

Faeces for bacterial monitoring were sampled at the beginning of the experiment at day 7 (1 week of oregano and $\mathrm{X}$ tract $^{\mathrm{TM}}$ administration), day 21 (3 weeks of oregano and $\mathrm{Xtract}^{\mathrm{TM}}$ administration) and day 42 (3 weeks after discontinuation of oregano and Xtract ${ }^{\mathrm{TM}}$ administrations). The samples were treated by standard microbiological method (International Organization for Standardization-ISO) using appropriate dilutions in Ringer solution ( $\mathrm{pH}$ 7.0, Oxoid Ltd., Basingstoke, Hampshire, England). The appropriate dilutions were plated onto M-Enterococcus agar (Becton \& Dickinson, Cockeysville, USA) to detect enterococci. Lactic acid bacteria (LAB) were counted using de Man-Rogose-Sharp agar. Baird-Parker agar supplemented with egg yolk tellurite solution (Becton \& Dickinson) was used to enumerate coagulase-positive staphylococci (CoPS, including Staphylococcus aureus). Mannitol Salt Agar (Difco Laboratories, Detroit, USA) was used for coagulase-negative staphylococci (CoNS). Clostridium difficile agar with selective supplement (SR0096E) and 7\% (v/v) defibrinated horse blood (SR0050, Oxoid Ltd., Basingstoke, Hampshire, England) was used to count Clostridium-like bacteria; to enumerate coliforms MacConkey agar (Becton \& Dickinson) was used. The plates were incubated at $30{ }^{\circ} \mathrm{C}$ and/or $37{ }^{\circ} \mathrm{C}$ 


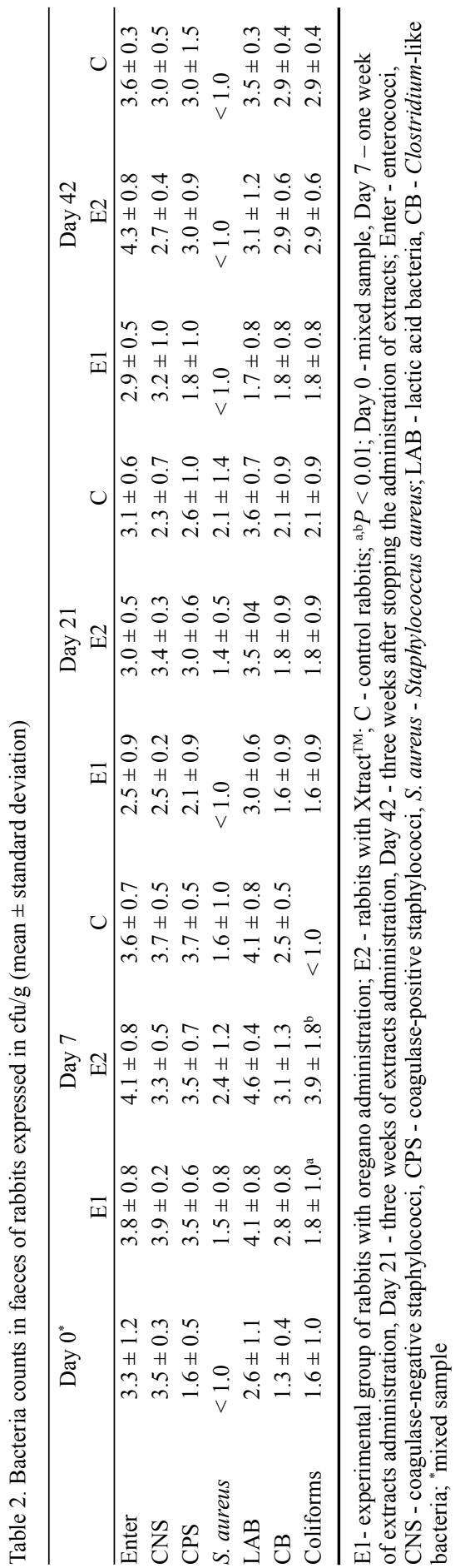

for 24-48 $\mathrm{h}$ depending on the bacterial genera and the counts of bacteria isolated from feaces were expressed as $\log _{10}$ of colony forming units $(\mathrm{CFU})$ per gram $\pm \mathrm{SD}$.

Selected animals in each group were killed at days 21 (3 weeks of oregano and Xtract ${ }^{\mathrm{TM}}$ administration) and 42 (3 weeks after stopping of oregano and $\mathrm{Xtract}^{\mathrm{TM}}$ administration) by cutting the jugular vein and the carotid artery after electroanaesthesia ( $90 \mathrm{~V}$ for $5 \mathrm{~s}$ ) and caecal contents were collected to count bacteria. The samples of caecal contents were treated and bacteria expressed as described.

Biochemical and immunological indicators, lactic acid and volatile fatty acids measurement, nutritional variables

Biochemical and immunological indicators were examined at the beginning of the experiment (day 0), at days 21 and 42 . Serum concentrations of total proteins ( $\mathrm{g} / \mathrm{l}$, TP 245) and total lipids (g/l, TL 100), cholesterol (mmol/1, CH 200), glucose (mmol/1, GL 2623), calcium (mmol/1, CA 590) were measured using commercial kits Randox (Randox Laboratories Ltd., $\mathrm{UK}$ ) and the level of glutathione peroxidase ( $\mathrm{GPx}, \mathrm{U} / \mathrm{gHb}$, RS 504) was determined using a Ransel standard set (Randox Laboratories LtD., UK).

The phagocytic activity (PA) was assessed by direct counting procedure using microspheric hydrophilic particles (MSHP). Ingestion of MSHP by polymorphonuclear cells $(\mathrm{PMN})$ was determined using a modified test described by Vetvicka et al. (1982). Blood smears were preparated and stained in accordance with May-Grünwald and GiemsaRomanowski (Hrubiško 1981).

Lactic acid (g/100g) and volatile fatty acid values (acetic, propionic and butyric acids in $\mathrm{mmol} / \mathrm{l}$ ) were determined using gas chromatography (glass column with inner standard: isocapronic acid- column SP $1200 \mathrm{H}_{3} \mathrm{PO}_{4}$; for lactic acid column contained $10-15 \%$ dimethylstearamid) from the samples of caecal content at days 21 and 42 .

Nutritional variables such as weight $(\mathrm{g})$, weight gain $(\mathrm{g})$, feed conversion $(\mathrm{g} / \mathrm{g})$, feed intake (g/day) and mortality (n) were checked daily.

\section{Eimeria sp. oocysts detection}

Eimeria sp. oocysts were enumerated in the faecal samples microscopically at the start of the experiment (day $0-1)$, at days 7,21 and 42 of the experiment and expressed in counts of oocysts per $1 \mathrm{~g}$ of faeces (OPG). The samples were evaluated by the quantitative flotation technique - modified McMaster method (Ministry of Agriculture, Fisheries and Food, Manual of veterinary parasitological laboratory techniques, 1986).

\section{Statistical analysis}

The results are quoted as mean $\pm \mathrm{SD}$ (standard deviation), statistical evaluation of the results was performed by the oneway ANOVA post-hoc Tukey test $(P<0.05,0.01)$.

\section{Results}

The counts of CoNS in E1 were slightly decreased compared to E2 at days 21 and 42 . The counts of CoPS were also lower in E1 compared to E2 and control at day 42. Moreover, in experimental groups, the reduction of Clostridium-like bacteria were found at day 21 
(in E1 and E2) as well as at day 42 (in E1) compared to control. Coliforms in E1 were significantly lower than in E2 group $(P$ $<0.01$, Table 2 ) at day 7 . The bacterial counts in caecum were lower (from 2 to $3 \mathrm{log}$ cycle) compared to those in faeces and no significant changes in bacteria were noted.

Biochemical indicators were not influenced by administration of additives (Table 3 ). In caecum of rabbits in both groups E1 and E2, higher values of acetic, propionic and butyric acids were noted at days 21 and 42 (Table 4); moreover, a significant increase $(P<0.01)$ of the butyric acid value was observed in E2 compared to control.

The value of phagocytic activity (PA) was higher in E1 (21.6 $\pm 0.51 \%)$ compared to group E2 $(13.4 \pm 0.51 \%)$ at day 21 of oregano and Xtract ${ }^{\mathrm{TM}}$ additions. At the end of experiment PA in E1 reached $18.8 \pm 0.37 \%$ compared to E2 group $(16.6 \pm 0.51 \%)$.

Concerning the nutritional variables (Table 5), in E1 as well as E2 were observed higher $(P<0.05)$ feed conversion ratio at day 21, higher final weight in E1 at day 42, higher daily weight gain in E1 and E2 at day 42 and lower mortality in E1 and E2 at day 42 compared to control.

The anti-coccidial effect was recorded in both experimental groups at days 21 and 42 compared to control. In E1 250 OPG were counted, whereas in E2 33.4 OPG were found, and in the control group 1306.7 OPG were counted at day 21 . The oocysts were also reduced in both experimental groups at day 42 (183.4 OPG were counted in E1, 133.3 OPG in E2) compared to control (1435.7 OPG). Comparison between E1 and E2 showed at both days of sampling, a slight decrease of Eimeria sp. oocysts in E1 (from $250 \mathrm{OPG}$ at day 21 to $183.4 \mathrm{OPG}$ at day 42), whereas an increase of oocysts was noted in E2 (from 33.4 OPG at day 21 to 133.3 OPG at day 42).

The lowest values of GPx were measured in E1 $(207.1 \pm 67.3 \mathrm{U} /$ $\mathrm{gHb})$ compared to E2 $(275.5 \pm 114.8 \mathrm{U} / \mathrm{gHb})$ and control $(250.2$ $\pm 109.8 \mathrm{U} / \mathrm{gHb})$ at day 21 . Also the lowest values of GPx were observed in E1 (216.1 \pm 67.24$)$ compared to E2 $(267.1 \pm 101.9 \mathrm{U} /$ $\mathrm{gHb})$ as well as control $(265.4 \pm 135.7 \mathrm{U} / \mathrm{gHb})$ at day 42 .

\section{Discussion}

A decrease of CoNS and CoPS was observed in oregano group E1 compared to E2 and control. The administration of oregano plant extract lead to significant anti-coliforms $(P<0.01)$ and anti-clostridial effect. There are many studies showing the antibacterial potential of the oregano essential oil (its components such as carvacrol or its isomer thymol) in food and feed (Burt 2004). Marcin et al. (2006a) reported the inhibitory activity of oregano aromatic oils against pig isolates E. coli S143 and Salmonella enterica var. Enteritidis. In addition, Bozin et al. (2006) showed the in vitro antibacterial activity expressed by oregano essential oil on multiresistant strains of E. coli. 
Table 4. Values (mean \pm standard deviation) of volatile fatty acids in the caecum content after administration of oregano extract and Xtract ${ }^{\mathrm{TM}}$ (at day 21) and at the end of the experiment (3 weeks after discontinuing administration of oregano and $\mathrm{Xtract}^{\mathrm{TM}}$ at day 42 )

\begin{tabular}{llcc}
\hline Group & Volatile fatty acid & Day 21 & Day 42 \\
\hline E1 & Lactic acid (g/100g) & $0.049 \pm 0.001^{*}$ & $0.024 \pm 0.003$ \\
& Acetic acid (mmol/l) & $4.966 \pm 0.721$ & $6.063 \pm 0.726$ \\
& Propionic acid (mmol/l) & $0.372 \pm 0.066$ & $0.527 \pm 0.077$ \\
& Butyric acid (mmol/l) & $1.374 \pm 0.044$ & $1.679 \pm 0.142$ \\
E2 & Lactic acid (g/100 g) & $0.042 \pm 0.009$ & $0.042 \pm 0.003$ \\
& Acetic acid (mmol/l) & $5.910 \pm 0.411$ & $5.222 \pm 0.557$ \\
& Propionic acid (mmol/l) & $0.380 \pm 0.027$ & $0.455 \pm 0.052$ \\
& Butyric acid (mmol/l) & $1.808 \pm 0.189^{\mathrm{a}}$ & $1.585 \pm 0.034$ \\
$\mathrm{C}$ & Lactic acid (g/100 g) & $0.041 \pm 0.005$ & $0.044 \pm 0.005$ \\
& Acetic acid (mmol/l) & $4.188 \pm 1.115$ & $4.949 \pm 1.490$ \\
& Propionic acid (mmol/l) & $0.275 \pm 0.027$ & $0.451 \pm 0.244$ \\
& Butyric acid (mmol/l) & $1.095 \pm 0.113^{\mathrm{b}}$ & $1.238 \pm 0.507$ \\
\hline
\end{tabular}

E1 - experimental group (oregano; $n=3)$; E2 - experimental group $\left(\mathrm{Xtract}^{\mathrm{TM}} ; \mathrm{n}=3\right)$; $\mathrm{C}$ - $\operatorname{control}$ group $(\mathrm{n}=3)$; a,b $P<0.01$

Table 5. Nutrition indicators (mean \pm standard deviation) of rabbits in response to dietary supplementation of oregano (E1) and $\mathrm{Xtract}^{\mathrm{TM}}$ (E2) compared to control group

\begin{tabular}{lccc}
\hline Nutrition indicators & E1 (oregano) & E2 (Xtract $^{\mathrm{TM}}$ ) & C (control group) \\
\hline Initial weight $(\mathrm{g})$ & $950 \pm 100$ & $968 \pm 120$ & $964 \pm 109$ \\
Final weight $(\mathrm{g})$ & $2521 \pm 263$ & $2460 \pm 225$ & $2465 \pm 180$ \\
Daily weight gain (g/day) & 38.9 & 40.48 & 38.29 \\
Feed conversion ratio at day 21 (g/g) & $3.01 \pm 0.03^{\mathrm{a}}$ & $2.99 \pm 0.02$ & $2.81 \pm 0.07^{\mathrm{b}}$ \\
Feed conversion ratio at day 42 (g/g) & $3.49 \pm 0.02$ & $3.56 \pm 0.04$ & $3.63 \pm 0.11$ \\
Daily feed intake (g/day) & $130.5 \pm 10.2$ & $126.5 \pm 13.6$ & $129.4 \pm 8.5$ \\
Mortality $(\mathrm{n})$ & 2 & 3 & 5 \\
\hline
\end{tabular}

a,b $P<0.05$

The feeding of either oregano or Xtract ${ }^{\mathrm{TM}}$ in rabbits in our study did not influence the biochemical indicators; neither did it have a negative effect on the health status and growth performance of rabbits. Marcin et al. (2006b) also reported positive influence on growth performances and the incidence of diarrhoeal diseases in the experimental weaned pigs administrating aromatic oils from oregano, clove and cinnamon.

It can be stated that oregano administration has an immuno-stimulatory effect. Moreover, the higher PA was also demonstrated in blood samples of rabbits after sage administration (Szabóová et al. 2008) and after sage administration with bacteriocin-producing strain Enterococcus faecium CCM 4231 and its bacteriocin enterocin 4231 (Szabó ová et al. 2011).

Eimeriosis in rabbit breeds presents a serious health and economic problem. Our study showed that both the oregano plant extract and Xtract ${ }^{\mathrm{TM}}$ administration lead to reduction of Eimeria sp. oocysts. The mechanisms of reduction of Eimeria sp. oocysts in the intestinal tract after administration of natural substances have not been rigorously studied up to now. However, we hypothesise that plant extracts/essential oils inhibit target cells in the membrane, depleting the transmembrane potential and/ or the $\mathrm{pH}$ gradient, which results in the leakage of cellular materials and destruction of oocysts (Cleveland et al. 2001). Giannenas et al. (2003) reported reduction of Eimeria tenella oocysts after dietary supplementation with oregano essential oil in 
broiler chicken. The anti-coccidial effect $(P<0.05)$ of another natural substance, green tea-based diets were also evaluated in chickens (Seung et al. 2007). Administration of chamomile essential oil (Simonová et al. 2006) as well as a plant extract of sage (member the Labiatae family; Szabóová et al. 2008) resulted in the reduction of Eimeria sp. oocysts in faeces of rabbits.

The beneficial effect of oregano plant extract administration was manifested by antimicrobial activity, by the increase of phagocytic activity as well as by a new phenomenon, the anti-coccidial effect in rabbits.

\section{Acknowledgements}

This work was supported by the Slovak Scientific Agency VEGA (project no. 2/0002/11) and the Slovak Research and Development Agency (project no. SK-HU-0006-08). The authors thank Mrs. M. Bodnárová and Dr. M. Haviarová for their excellent technical assistance. We are grateful to Dr. V. Parkányi, Dr. R. Jurčík, Ing. L. Ondruška as well as Dr. J. Rafay from Animal Production Research Centre in Nitra for their help in blood sampling. We are also grateful to Dr. Jana Poráčová and Dr. Ivan Šalamon (Department of Biology, University of Prešov, Slovakia) for supplying the oregano extract.

\section{References}

Bozin B, Mimica-Dukic N, Simin N, Anackov G 2006: Characterization of the volatile composition of essentials oils of some lamiaceae spices and the antimicrobial and antioxidant activities of the entire oils. J Agric Food Chem 54: 1822-1828

Burt SA 2004: Essential oils: their antibacterial properties and potential applications in foods - a review. Int J Food Microbiol 94: 223-253

Cleveland J, Montville TJ, Nes IF, Chikindas ML 2001: Bacteriocins: safe, natural antimicrobials for food preservation. Int J Food Microbiol 71: 1-20

Giannenas I, Florou-Paneri P, Papazahariadou M, Christaki E, Botsoglou NA, Spais AB 2003: Effect of dietary supplementation with oregano essential oil on performance of broilers after experimental infection with Eimeria enella. Arch Anim Nutr 57: 99-106

Goliaris AH, Chatzopoulou PS, Katsiotis ST 2002: Production of new Greek oregano clones and analysis of their essential oils. J Herb Spices Medic Plants 10: 29-35

Hrubiško M 1981: Some tests intended for investigation of the function of leukocytes. Haematology and Transfusiology. Osveta, Martin, Slovak Republic, pp. 228-236

Jones FA 1996: Herbs-useful plants. Their role in history and today. Eur J Gastroenterol Hepatol 8: 1227-1231

Lambert RJW, Skandamis PN, Coote PJ, Nychas GJE 2001: A study of the minimum inhibitory concentration and mode of action of oregano essentials oil, thymol and carvacrol. J Appl Microbiol 91: 453-462

Lewis MR, Rose SP, Mackenzie AM, Tucker LA 2003: Effects of dietary inclusion of plant extracts on the growth performance of male broiler chickens. Brit Poult Sci 44: 43-44

Lis-Balchin M, Deans SG 1997: Bioactivity of selected essential oils against Listeria monocytogenes. J Appl Microbiol 84: 538-544

Marcin A, Lauková A, Mati R 2006a: Comparison of the effects of Enterococcus faecium and aromatic oils from sage and oregano on growth performance and diarrhoea diseases of weaned pigs. Biologia Bratislava 61: 789-795

Marcin A, Sústriková A, Mati R 2006b: The effects of aromatic oils on growth performance and physiological parameters in the intestine of weaned pigs. Slov J Anim Sci 39: 103-107

Ministry of Agriculture, Fisheries and Food 1986: Manual of veterinary parasitological laboratory techniques, 3rd ed. London: Her Majesty‘s Stationery Office (HMSO), 160 p.

Sarac N, Ugur A, Duru ME, Varol O 2009: Antimicrobial activity, antioxidant activity and chemical composition of Origanum onites L. and Origanum vulgare L. ssp. hirtum (Link) ietswaart from Mugla (Turkey). Acta Horticul 826: 397-404

Seung IJ, Moo-Hyung J, Hyung SL, Rami AD, Il-Keung K, Suk K, Wongi M 2007: Anticoccidial effect of green tea-based diets against Eimeria maxima. Vet Parasitol 15: 172-175

Simonová M, Strompfová V, Marciňáková M, Haviarová M, Faix Š, Vasilková Z, Lauková A, Šalamon I 2006: The experimental application of chamomile essential oil in rabbits. Proceedings of the $1^{\text {st }}$ International symposium on Chamomile Research, Development and Production; 2006 7-10 June; Prešov, Slovak Republic, 122 p.

Szabóová R, Lauková A, Chrastinová L, Simonová M, Strompfová V, Haviarová M, Plachá I, Faix Š, Vasilková Z, Chrenková M, Rafay J 2008: Experimental application of sage in rabbit husbandry. Acta Vet Brno 77: 581-588

Szabóová R, Lauková A, Chrastinová L', Strompfová V, Pogány Simonová M, Vasilková Z, Čobanová K, Plachá I, Chrenková M 2011: Effect of combined administration of enterocin 4231 and sage in rabbits. Pol J Vet Sci 14: $359-366$

Vetvička V, Fornousek L, Kopeček J, Kamínková J, Kašpárek L, Vránová M 1982: Phagocytosis of human blood leukocytes, a simple micro method. Immunol Lett 5: 97-100 